\title{
NILAI SUFISTIK DALAM ALBUM SURGAMU YANG DIPOPULERKAN BAND UNGU
}

\author{
Muhammad Khudloifi Ghifrillah, Taufik Nurhadi \\ Pendidikan Bahasa dan Sastra Indonesia, Fakultas keguruan dan Ilmu Pendidikan, \\ Universitas PGRI Adi Buana Surabaya \\ khudloifi@gmail.com, taufiknurhadi70@gmail.com
}

\begin{abstract}
ABSTRAK
Penelitian dengan judul "Nilai Sufistik dalam Album SurgaMu Karya Ungu" ini memiliki tujuan untuk mendeskripsikan nilai sufistik dalam album SurgaMu karya Ungu terkait dengan syauq, mahabbah, Tarkussyahwat, Muhasabatun Nafs dan At-Taubat. Melalui teori tasawwuf dan menjadikan album SurgaMu sebagai sumber datanya. Dalam album SurgaMu, yang merupakan salah satu bentuk syair ini mengandung banyak nilai sufistik pada lirik lagu-lagunya. Di antaranya yaitu Kerinduan terhadap Tuhan (Syauq), Cinta kepada Tuhan (Mahabbah), Menahawan Hawa Nafsu (Tarkussyahwat), Intropeksi Diri (muhasabatun nafs) dan Taubat (At-Taubah).
\end{abstract}

Kata Kunci: Nilai Sufistik, syair, Syauq, Mahabbah, Tarkussyahwat, Muhasabatun Nafs dan At-Taubat.

\section{PENDAHULUAN}

Karya sastra adalah hasil karya manusia yang dituangkan dari perasaan, pemikiran melalui pengalaman atau potret sosial yang menggunakan bahasa kreatif dan imajinatif. Sastra diciptakan bukanlah dari sesuatu yang kosong, tetapi sastra diciptakan dari ruang lingkup masyarakat. Sastra diciptakan oleh manusia untuk dinikmati, dipahami, dan dimanfaatkan oleh masyarakat. Perkembangan suatu karya sastra selalu dikaitkan dengan kehidupan manusia karena karya sastra mencakup hubungan antar manusia, antar masyarakat, antar peristiwa yang terjadi dalam batin seseorang

Bentuk sastra berarti cara dan gaya dalam penyususan dan pengaturan bagianbagian karangan; pola struktural karya sastra. Ke dalamnya dapat digolongkan tiga bentuk; puisi, prosa, dan drama. Menurut Pradopo (1990) puisi merupakan rekaman dan interpretasi pengalaman manusia yang penting dan diubah dalam wujud yang berkesan.

Dalam album atau lirik SurgaMu terdapat kedekatan antara manusia dengan Tuhan. Diartikan dekat dengan Tuhan adalah manusia yang bersungguh-sunguh taat beribadah kepada Allah, mencintai Allah SWT dan menjaga hubungan dengan-Nya, dengan bertujuan untuk membersihkan penyakit hati dalam diri manusia dari pengaruh duniawi, hal ini dapat disebutkan sebagai ahli tasawwuf. Kemunculan istilah tasawwuf baru dikenal sebelum akhir abad ke-2 $\mathrm{H}$ atau sebelum tahun $815 \mathrm{M}$.

Sastra sufistik adalah ragam karya sastra yang mendapat pengaruh kuat dari sastra sufi atau sastra tasawuf, termasuk sistem pencitraan, penggunaan lambang, dan metafora (Hadi W.M., 1999).

Hal menarik yang menjadi alasan peneliti memilih judul "Nilai Sufistik pada Album SurgaMu yang Dipopulerkan Band Ungu” yaitu, di dalam album SurgaMu tersebut menggambarkan manusia yang bergelimang dosa yang akan takut siksa 
neraka dan memohon ingin kembali mendekatkan diri pada-Nya. Hazim (2012:15) menyatakan walaupun kita bukan termasuk dari golongan sufi, tetapi kita tetap tidak diperbolehkan mengosongkan diri kita untuk tetap belajar dan mengamalkan tasawwuf. Minimal, kita tahu bagaimana tata cara beretika dengan sesama manusia, lingkungan, dan dengan Allah SWT. Sehingga, akan tumbuh perasaan taqwa.

Album yang berjudul "SurgaMu" yang dipopulerkan band Ungu sangatlah tepat jika dikaji dari segi tasawwuf. Karena di dalam album "SurgaMu" mengungkapkan kesungguhan manusia memohon ampun kepada Tuhan atas segala dosa yang telah dilalui. Dengan bertujuan untuk mendekatkan diri dan senantiasa ingat kepada Allah SWT. Bahwa hidup di dunia ini hanyalah sementara tidak ada yang abadi, semua yang ada bumi ini hanyalah milikNya dan akan pula kembali pada-Nya.

\section{METODE PENELITIAN}

Data penelitian ini diambil dari salah satu karya sastra yang berbentuk puisi atau (album) lagu. Album yang dijadikan penelitian ini adalah berjudul "Surga-Mu" yang dipopulerkan band Ungu. Data yang akan diambil oleh peneliti berupa lirik dalam album tersebut yang mengandung unsur-unsur sufistiknya.

Sumber data penelitian ini adalah sebuah album berjudul "Surga-Mu" karya Ungu. Yang diterbitkan oleh Trinity Optima Production Jakarta tahun 2006. Dengan jumlah sebanyak 5 lagu.

Teknik pengumpulan data yang diisi dalam penelitian ini adalah teknik baca dan catat. Teknik baca adalah peneliti membaca terlebih dahulu lirik album yang berjudul "Surga-Mu" karya Ungu yang akan diteliti dengan pendekatan sufistik sampai selesai. Teknik catat merupakan tindakan peneliti untuk mencatat lirik yang paling menonjol untuk mengumpulkan data yang berkaitan dengan tujuan penelitian.

Teknik analisis data dalam penelitian ini menggunakan metode deskriptif dan analisis. Analisis data ditinjau dari segi klasifikasi yakni data-data yang telah diklasifikasi lalu dideskripsikan dengan apa adanya tanpa adanya penilaian, kemudian dilakukan penganalisisan. Analisis data merupakan tahap inti dari penelitian kualitatif. Metode deskriptif dan analisis digunakan untuk mendeskripsikan nilai sufistik yang ada dalam album "Surga-Mu" yang dipopulerkan band Ungu.

\section{PEMBAHASAN}

Berdasarkan hasil penelitian dalam album SurgaMu karya Ungu, ditinjau dari nilai sufistik, peneliti menemukan hasil penelitian di antaranya:

1. Nilai Sufistik Terkait dengan Syauq

Dalam album SurgaMu karya band Ungu, nilai sufistik yang terkait dengan syauq tampak pada gumam seorang manusia mengenai kerinduannya terhadap Tuhan. Rasa rindu yang bersumber dari hati dan merupakan buah cinta yang mendalam, orang yang selalu merindu akan merasakan kehausan cinta. Dia akan selalu berdoa dan berusaha untuk mengubah segalannya melalui kerinduan agar menjadi lebih baik lagi. Hal tersebut terkandung dalam lagu yang berjudul Doa dan SurgaMu. Berikut kutipan lirik lagu Do'a dan SurgaMu beserta penjelasannya. 


\section{"Tuhan jamahlah hatiku yang kering dan hampa tanpa kasih"}

\section{"Tunjukkan aku jalan lurusMu, untuk menggapai surgaMu"}

Menjelaskan tentang gumam seorang hamba yang merasa jauh dariNya, lupa atas segala kemurahan dan kasih sayangNya. Memohon kepada Tuhan untuk menyentuh hatinya yang hampa akan kasihNya, meminta agar Tuhan selalu hidup di dalam hatinya.

2. Nilai Sufistik Terkait dengan Mahabbah

Dalam album SurgaMu karya band Ungu, nilai sufistik yang terkait dengan mahabbah tampak pada pujian seorang hamba kepada Tuhannya. Cinta terlahir dari lubuk hati yang paling dalam, hati yang suci, tulus dan ikhlas. Hal tersebut terkandung dalam lagu yang berjudul SurgaMu. Berikut kutipan lirik beserta penjelasannya.

\section{"Allahu Akbar Allah Maha Besar Ku memujamu di setiap waktu"}

Menunjukkan bahwa Allah adalah Maha Agung, Maha Esa, yang pantas disembah dan dipuja setiap waktu. Ada berbagai hal untuk memuja, di antaranya menyebut kalimat-kalimat thoyyibah, mengucap rasa syukur dan melalui beribadat kepadaNya. Karena Dia adalah Sang Khaliq, Sang Maha Pencipta segala hal dalam bentuk apapun, menjadikan pagi menjadi malam dan malam kembali pagi, semua itu atas kehendak dan kuasaNya.

3. Nilai Sufistik Terkait dengan Tarkussyahwat

Dalam album SurgaMu karya band Ungu, nilai sufistik yang terkait dengan tarkussyahwat tampak pada rasa syukur seorang hamba karena telah melewati dan melawan hawa nafsu di bulan Ramadhan selama satu bulan. Tarkussyahwat ini tidak harus dilakukan pada bulan ramadhan saja, melainkan di setiap waktu. Karena tarkussyahwat merupakan cara untuk menghindari atau menahan dari segala penyakit hati. Hal tersebut terkandung dalam lagu yang berjudul Selamat Lebaran. Berikut kutipan lirik beserta penjelasannya.

\section{"Mari kita saling bermaafan \\ Di hari yang indah fitri nan bahagia \\ Sebulan lamanya kita menahan nafsu \\ Dan cobaan di bulan Ramadhan"}

Menjelaskan tentang suatu ajakan untuk saling bermaafan di hari Raya Idul Fitri. Sebagai manusia yang tak luput dari kesalahan, ada baiknya jika saling memohon maaf meski merasa tidak pernah melakukan kesalahan dengan kesengajaan

\section{Nilai Sufistik Terkait dengan Muhâsabatun Nafs}

Dalam album SurgaMu karya band Ungu, nilai sufistik yang terkait dengan muhasabatun nafs tampak pada kesadaran seorang hamba tentang dirinya yang merupakan manusia biasa dan memiliki banyak dosa. Upaya untuk memperhitungkan, menilai, mempertimbangkan atau menelaah ihwal diri sendiri. 
(kesadaran hati). Kesadaran akan hati yang sudah buta karna wanita, harta, dan tahta. Sebagai seorang insan kita harus sadar diri terhadap ihwal kebaikan dalam hidup kita, bertawakkal dan berdoa kepada Tuhan. Hal tersebut terkandung dalam lagu yang berjudul SurgaMu, Doa, Selamat Lebaran, dan Andai Ku Tahu. Berikut kutipan lirik beserta penjelasannya.

\section{" Segala yang ada dalam hidupku \\ Ku sadari semua milikMu \\ Ku hanya hambaMu yang berlumur dosa "}

Menunjukkan bahwa dunia dan seluruh isinya baik yang bernyawa maupun yang tidak bernyawa adalah milikNya. Semua tercipta karena dzatNya, seharusnya kita sadar bahwa apa yang kita punya saat ini, belum tentu kita akan membawanya sampai dihari kelak nanti, semua yang kita punya hanyalah sementara tidak lain hanya titipan dariNya. Kita harus sering menimbang diri, bertafakkur dan bersyukur, karena semua yang hidup adalah karena kuasaNya. Karena hakikat hidup adalah hidup untukNya dan mati pun untukNya. Kita sebagai manusia biasa tidak luput dari kesalahan, baik kepada sesama manusia, alam, maupun kepada Sang Pencipta.

\section{" Tuhan jamahlah hatiku Yang kering dan hampa tanpa kasih Atas kuasaMu ku terlahir Dan hanya padaMu ku kembali ",}

Menjelaskan tentang rintihan seorang hamba yang memanjatkan do'a, memohon kepada Tuhan untuk menyentuh hatinya yang hampa akan kasihNya. Meminta agar Tuhan selalu hidup dalam hatinya. Memberikan rahmatNya untuk menerangi jalan hidupNya karena tanpa rahmat dariNya kita semua tersesat, terperangkap dan mungkin juga bisa mati. Kita harus mempercayai bahwa semua terlahir atas kuasaNya, semua berakhir juga atas kehendakNya dan kita semua pasti kembali kepadaNya.

\section{"Mari kita saling memaafkan Dosa-dosa yang pernah terbuat,}

Mengajak untuk saling bermaafan dari segala dosa yang pernah diperbuat baik sengaja maupun tidak sengaja. Dalam Islam kita harus wajib meminta maaf kepada seorang apabila kita mempunyai salah dan wajib pula bagi orang yang menerima maaf untuk dimaafkan. Sebaik-baik manusia adalah orang mau meminta maaf dan mengakui kesalahannya dan sebaik-baik manusia adalah orang yang pemaaf.

“Aku manusia yang takut neraka Namun aku juga tak pantas di surga ",

Menunjukkan seorang hamba yang penuh dengan sesal, penuh dengan dosa tidak layak masuk ke dalam surga namun juga tiada kuat menerima siksa api 
neraka. Bertaubat dan memohon ampun atas segala dosa-dosa semasa hidup, sesungguhnya Engkau adalah Maha Pengasih, Maha Penyayang dan Maha Pengampun atas segala dosa. Kita manusia harus sering menimbang diri, siapalah diri kita kalau tanpa DzatNya.

5. Nilai Sufistik Terkait dengan At-Taubat

Dalam album SurgaMu karya Ungu, nilai sufistik yang terkait dengan at-taubat tampak pada permohonan ampunan seorang hamba kepada Tuhannya atas segala dosa yang telah diperbuat melalui doa. Berikut kutipan lirik beserta penjelasannya.

\section{" Hanyalah pada-Mu tempat berteduh Memohon ridlo dan ampunanMu "}

Menunjukkan bahwa hanya kepadaNya kita menyembah, hanya kepadaNya pula kita berkeluh kesah, meminta dan memohon ampun. Tempat untuk bertafakkur, berteduh dan berlindung. Kita sebagai manusia haruslah pandai menanamkan rasa syukur kepada Tuhan meski terkadang hidup selalu dihiasi dengan ujian dan cobaan, karena di balik itu semua pasti ada hikmah yang tersimpan dan Tuhan tidak akan memberi cobaan dan ujian melebihi batas kemampuan manusia itu sendiri. Kita harus yakin bahwa ujian dan cobaan adalah cara Tuhan untuk mengubah diri kita menjadi manusia jauh lebih baik lagi.

\section{“ Izinkan aku mengucap kata taubat padaMu Ampuni aku dari segala dosa-dosaku Ampuni aku menangis ku bertaubat padaMu "}

Menunjukkan seorang hamba yang berdoa. Tuhan, izinkan aku mengucap kata taubatku sebelum ajal datang menjemputku, ampuni segala dosa Tuhan. Menangis mengingat dosa-dosa yang menyatu dengan tubuh. Karena takut, bila mati nanti membawa dosa. Memohon ampun untuk mengucap kata taubat kepadaNya, sebelum kembali kepadaNya dengan membawa lumuran dosa.

\section{“ Hanya padaMu ku memohon Dan hanya padaMu ku bersujud Tunjukkan aku menuju jalan lurusMu Agar aku dapat wujudkan taubatku Terangi aku dalam gelapnya duniaku Agar aku bisa dapatkan ridlaMu "}

Menunjukkan bahwa kita manusia hanya bisa pasrah kepadaNya, baik buruknya dalam suatu kehidupan adalah skenario Tuhan. Hanya kepadaNya tempat untuk menimbang diri, bersujud dan memohon ampun dari segala dosa. Wujud dari bertaubat adalah berdoa memohon ampun kepada Tuhan dari segala dosa dan tidak mengulangi pada kesalahan yang sama. Meminta kepada Tuhan untuk menunjukkan jalan lurusNya. Menerangi setiap langkah dalam melewati jalan kehidupan untuk kebaikan menuju ridlaNya. Memohon dengan maksud agar dibukakan pintu taubat. Diwujudkan taubatnya. Karena taubat adalah suatu sarana dan tempat ma'rifatullah untuk menuju dan mencapai tingkat yang tertinggi. 
Sesungguhnya pintu taubat dibuka hingga tanda-tanda kiamat tiba, yang kita juga tidak mengetahui kapan kemunculannya. Manusia tidak pernah luput dari dosa, oleh sebab itu, sebaik-baiknya manusia adalah dia yang bertaubat.

Nilai sufistik adalah suatu nilai yang terkandung dalam suatu makna yang berisikan tentang hubungan antara manusia dengan Tuhan dalam mencapai derajat yang a'rifin, auliya' dan gelar paling mulia di sisiNya. Dalam mempelajari nilai sufistik dibutuhkan suatu cara untuk membedah atau memperdalam agar memudahkan dalam proses meneliti, yaitu dengan mempelajari ilmu tasawwuf. Menurut Sayyid Abi Bakar Ibnu Muhammad Syatha (2003:1) Ilmu tasawwuf ialah ilmu yang membahas secara karakteristik sifat dan sikap manusia baik membersihkan hati dan jiwanya sebagai tujuan utama pengamalan ilmu tasawwuf dan pintu gerbang memasuki alam shufiyah. Dengan cara ini akan mudah bagi manusia menghiasi jiwanya dengan sifat-sifat yang mulia bertaqarrub dan bermusyahadah dengan Allah SWT.

Orang disebut dengan sufi adalah orang yang mendekatkan diri kepada Allah dengan jalan khusus atau beriyadloh dengan sungguh-sungguh. Tasawwuf sebagai ilmunya untuk menuju ke jalan sufi. Jalan sufi memiliki nilai di antaranya syauq, mahabbah, tarkussyahwat, muhasabatun nafs, at-taubat.

Syauq ialah ketertarikan hati untuk melihat yang dicintai. Ada pendapat lain yang mendefinisikan syauq sebagai api dari Allah yang dinyalakan di hati para kekasih-Nya hingga api itu mampu membakar apa yang ada di dalam hati mereka, mulai dari kekhawatiran, keinginan, sesuatu yang mendadak muncul, dan beraneka macam kebutuhan. Rindu itu timbul dari cinta. Bila seorang hamba sampai pada tingkat kerinduan ini, maka ia ingin sekali segera bertemu kematian, sebab ia sudah rindu ingin bertemu Tuhannya. Ia juga mulai merasakan telah bertemu dan terbang menemui ke hadirat Tuhannya.

Mahabbah (cinta) merupakan pijakkan bagi segenap kemulian hal, seperti halnya taubat yang merupakan dasar bagi kemulian Maqom. Karena Mahabbah pada dasarnya adalah anugerah yang menjadi dasar pijakan bagi segenap hal, kaum sufi menyebutnya sebagai anugerah-anugerah (Mawahib). Mahabbah adalah kecenderungan untuk memerhatikan keindahan atau kecantikan.Kaum Sufi menganggap mahabbah sebagai modal utama sekaligus mauhibah dari Allah Swt, untuk menuju ke jenjang ahwâl yang lebih tinggi. Konsep al-hub (cinta) pertama kali dicetuskan oleh seorang sufi wanita terkenal Rabi'atul Adawiyah $(96 \mathrm{H}-185$ $\mathrm{H})$, menyempurnakan dan meningkatkan versi zuhud, al khauf war raja' dari tokoh sufi Hasan Al Basri. Cinta yang suci murni adalah lebih tinggi dan lebih sempurna daripada al khauf war raja' (takut dan pengharapan), karena cinta yang suci murni tidak mengharapkan apa-apa dari Allah kecuali ridla-Nya. Menurut Rabi'atul Adawiyah, al hub itu merupakan cetusan dari perasaan rindu dan pasrah kepadaNya. Perasaan cinta yang menyelinap dalam lubuk hati Rabi'atul Adawiyah, menyebabkan dia mengorbankan seluruh hidupnya untuk mencintai Allah SWT.

Tarkussyahwat dalam pandangan tasawwuf ialah suatu ajaran untuk menahan hawa nafsu dan mengendalikannya ke jalan yang diridhai Tuhan. Untuk menahan atau memerangi tarkussyahwat yakni salah satunya dengan jalan berpuasa dan berdzikir sebagaimana yang sudah dilakukan oleh para sufi.

Muhasabatun nafs ialah upaya untuk memperhitungkan, menilai, mempertimbangkan, atau menelaah ihwal diri sendiri. Sadar diri terhadap 
kekuasan Tuhan, bahwasanya tiada Tuhan selain Dia. Dia yang pantas disembah, dipuji dan dicintai secara hakiki.

At-taubat adalah kembali kepada Allah setelah melakukan maksiat. Taubat marupakan rahmat Allah yang diberikan kepada hamba-Nya agar mereka dapat kembali kepada-Nya. Taubat adalah maqam awal yang harus dilalui oleh seorang salik. Sebelum mencapai maqam ini seorang salik tidak akan bisa mencapai maqam-maqam lainnya. Karena sebuah tujuan akhir tidak akan dapat dicapai tanpa adanya langkah awal atau pintu masuk yang benar. Pada tahap tawbah ini seorang sufi membersihkan dirinya (tazkiyyah al-nafs) daripada perilaku yang menimbulkan dosa dan rasa bersalah.

Hal menarik yang menjadi alasan peneliti adalah menggambarkan manusia yang bergelimang dosa yang akan takut siksa neraka dan memohon ingin kembali mendekatkan diri pada-Nya dalam kata lain adalah bertaubat. Abu Hazim (2012:15), menyatakan walaupun kita bukan termasuk dari golongan sufi, tetapi kita tetap tidak diperbolehkan mengosongkan diri kita untuk tetap belajar dan mengamalkan tasawwuf. Minimal, kita tahu bagaimana tata cara beretika dengan sesama manusia, lingkungan, dan dengan Allah SWT. Sehingga, akan tumbuh perasaan taqwa.

\section{SIMPULAN}

Berdasarkan hasil penelitian, peneliti menyimpulkan bahwa pada album SurgaMu karya Ungu terdapat nilai-nilai sufistik, yaitu :

1) Syauq (rindu) adalah ketertarikan hati untuk melihat yang dicintai. Ada pendapat lain yang mendefinisikan syauq sebagai api dari Allah yang dinyalakan di hati para kekasih-Nya hingga api itu mampu membakar apa yang ada di dalam hati mereka, mulai dari kekhawatiran, keinginan, sesuatu yang mendadak muncul, dan beraneka macam kebutuhan.

2) Mahabbah (cinta) merupakan pijakkan bagi segenap kemulian hal, seperti halnya taubat yang merupakan dasar bagi kemulian Maqom. Karena Mahabbah pada dasarnya adalah anugerah yang menjadi dasar pijakan bagi segenap hal, kaum sufi menyebutnya sebagai anugerah-anugerah (Mawahib). Mahabbah adalah kecenderungan untuk memerhatikan keindahan atau kecantikan.Kaum Sufi menganggap mahabbah sebagai modal utama sekaligus mauhibah dari Allah Swt, untuk menuju ke jenjang ahwâl yang lebih tinggi.

3) Tarkussyahwat ialah suatu ajaran untuk menahan hawa nafsu dan mengendalikannya ke jalan yang diridhai Tuhan. Untuk menahan atau memerangi tarkussyahwat yakni salah satunya dengan jalan berpuasa dan berdzikir sebagaimana yang sudah dilakukan oleh para sufi.

4) Muhasabatun nafs ialah upaya untuk memperhitungkan, menilai, mempertimbangkan, atau menelaah ihwal diri sendiri. Sadar diri terhadap kekuasan Tuhan, bahwasanya tiada Tuhan selain Dia. Dia yang pantas disembah, dipuji dan dicintai secara hakiki.

5) At-taubat adalah kembali kepada Allah setelah melakukan maksiat. Taubat marupakan rahmat Allah yang diberikan kepada hamba-Nya agar mereka dapat kembali kepada-Nya. Taubat adalah maqam awal yang harus dilalui oleh seorang salik. Sebelum mencapai maqam ini seorang salik tidak akan bisa mencapai maqam-maqam lainnya. 


\section{SARAN}

Berdasarkan hasil penelitian mengenai nilai sufistik pada album SurgaMu karya Ungu, peneliti memberikan saran yang bermanfaat bagi pembaca yakni dapat menambah wawasan tentang ilmu tasawwuf, dan dapat dijadikan acuan dalam menganalisis nilai sufistik yang terdapat dalam sebuah lagu oleh peneliti lain.

\section{DAFTAR PUSTAKA}

Al-Jailani, Abdul Qodir. 2008. Sirr Al Asrar Secret of The Secrets (Hakikat Segala Rahasia Kehidupan). Jakarta: Pustaka Islam Klasik.

Al-Qahthani, Said bin Musafir. 2006. Buku Putih Syaikh Abdul Qodir Al-Jailani. Jakarta: Darul Falah.

Al-Aziz S, Muhammad Saifulloh. 1998. Risalah Memahami Ilmu Tasawwuf. Gresik: Terbit Terang.

Alba, Cecep. 2012. Tasawuf dan Tarekat (Dimensi Esoteris Ajaran Islam). Bandung: Remaja Rosdakarya.

Achmad, Moch Djamaluddin. 2006. Jalan Menuju Allah. Jombang: Pustaka AlMuhibbin.

Falah, Maslahul. 2009. Jalan Menuju Ampunan. Bantul: Media Insani.

Farid, Ahmad. 2006. Taubat dalam Dosa. Jakarta: Dar Al-'Aqidah.

Hajjaj, Muhammad Fauqi. 2011. Tasawuf Islam \& Akhlak. Jakarta: Mathba'ah AlFajr Al-Jadid.

Hazim, Abu. 2012. Jalan Menuju Derajat Sufi. Bogor: Mu'jizat

Hadi, Abdul W.H. 1996. Sastra Sufi. cetakan ke-3. Jakarta: Pustaka Firdaus.

Khaliq, Abdurrahman Abdul dan Ihsan Illahi Zhahir. 2001. Pemikiran Sufisme (Di Bawah Bayang-bayang Fatamorgana). Jakarta: Amzah.

Nata, Abuddin. 2008. akhlak Tasawwuf. Jakarta: Raja Grafindo Persada.

Sunarto, Achmad. 2012. Kamus Lengkap Bahasa Indonesia. Rembang: Utama Prima.

Syatha, Sayyid Abi Bakar Ibnu Muhammad. 2003. Missi Suci Para Sufi. cetakan ke-3. Yogjakarta: Mitra Pustaka.

Teeuw, A. 1984. Sastra dan Ilmu Sastra. Jakarta: PT Girimukti Pasaka.

Tualeka, Hamzah. Dkk. 2011. Akhlak Tasawwuf. Surabaya: IAIN Sunan Ampel Press.

Likulros. 2012. "memahami istilah-istilah dalam tasawwuf". Http://likulros.blogspot.co.id/2012/10/memahami-istilah-istilah-dalamtasawuf Html. Diunduh pada 12/02/2016

Sufi-zone. 2010. "menyelami syauq". Html. Http://sufizone.blogspot.co.id/2010/05/menyelami-syauq Html. Diunduh pada $12 / 02 / 2016$.

Sufiroad. 2009. "mahabbah". Http://sufiroad.blogspot.co.id/2009/03/mahabbah Html. Diunduh pada 12/02/2016.

Ungucliquersind. 2013. "perjalanan dan terbentuknya band ungu". Html. Http://ungucliquersind.blogspot.co.id/2013/06/perjalanan-danterbentuknya-band-ungu

Html. Diunduh pada 12/02/2016. 